\title{
O AUTISMO PARA A PSICANÁLISE: DA CONCEPÇÃO CLÁSSICA À CONTEMPORÂNEA
}

\author{
AUTISM AS IN PSYCHOANALYSIS: FROM THE CLASSIC TO THE CONTEMPORARY CONCEPTION \\ AUTISMO PARA EL PSICOANÁLISIS: DE LA CONCEPCIÓN CLÁSICA A LA CONTEMPORÁNEA
}

\author{
Suzana Faleiro Barroso*
}

\begin{abstract}
RESUMO
$\mathrm{O}$ artigo aborda a diversidade do campo de saber do autismo em diferentes épocas e discute as bases epistemológicas que norteiam as noções de espectro e de estrutura autística, provenientes do discurso da ciência e da psicanálise de orientação lacaniana, respectivamente. Situa o percurso histórico da noção de autismo desde sua fundação no campo da psicopatologia clássica e sua evolução segundo uma abordagem psicodinâmica, junto aos analistas pós-freudianos. Identifica o autismo nas diferentes versões do DSM, no qual ele é reduzido a um déficit do neurodesenvolvimento. Examina a hipótese do autismo como estrutura clínica e discute alguns aspectos da sua distinção com relação à psicose. Demonstra o compromisso da pesquisa e da aplicação da psicanálise ao autismo, desde os anos cinquenta do século XX, enfatizando seus aspectos teóricos, éticos e clínicos.
\end{abstract}

Palavras-chave: Autismo. Psicopatologia. Classificaçôes diagnósticas. Espectro. Estrutura clínica.

\begin{abstract}
This article addresses the diversity of the field of knowledge on autism at different times and discusses the epistemological bases that guide the notions of spectrum and autistic structure, derived from the discourse of science and from the Lacan-oriented psychoanalysis, respectively. It spots the historical trajectory of the notion of autism since its foundation in the field of classical psychopathology and its evolution according to a psychodynamic approach, together with post-Freudian analysts. It identifies autism in different versions of the DSM, in which it is reduced to a deficit in neurodevelopment. It examines the hypothesis of autism as a clinical structure and discusses some aspects of its distinction in relation to psychosis. It demonstrates the commitment of research and the application of psychoanalysis to autism, since the fifties, emphasizing its theoretical, ethical and clinical aspects.
\end{abstract}

\footnotetext{
*Doutora em Teoria Psicanalítica pela Universidade Federal do Rio de Janeiro (UFRJ), membro da Escola Brasileira de Psicanálise e da Associação Mundial de Psicanálise, professora no Curso de Psicologia da Faculdade de Psicologia da Pontifícia Universidade Católica de Minas Gerais (PUC Minas), coordenadora do Curso de Especialização - Abordagem Psicanalítica do Autismo e Conexôes (Instituto de Educação Continuada da PUC Minas - IEC-PUC Minas), psicanalista, psicóloga. Endereço: Rua Ceará, 1735, ap. 1201 - Savassi, Belo Horizonte-MG, Brasil. CEP: 30150-311. E-mail: suzanafaleirobarroso@gmail.com.
} 
Keywords: Autism. Psychopathology. Diagnostic classifications. Spectrum. Clinical structure.

\section{RESUMEN}

El artículo aborda la diversidad del campo del conocimiento del autismo en diferentes momentos y discute las bases epistemológicas que guían las nociones de espectro y estructura autista, derivadas del discurso de la ciencia y el psicoanálisis de orientación lacaniana, respectivamente. Sitúa la trayectoria histórica de la noción de autismo desde su fundación en el campo de la psicopatología clásica y su evolución según un enfoque psicodinámico, junto con analistas post-freudianos. Identifica el autismo en diferentes versiones del DSM, en el que se reduce a un déficit en el desarrollo neurológico. Examina la hipótesis del autismo como estructura clínica y discute algunos aspectos de su distinción en relación a la psicosis. Demuestra el compromiso de la investigación y de la aplicación del psicoanálisis al autismo, desde los años cincuenta, enfatizando sus aspectos teóricos, éticos y clínicos.

Palabras clave: Autismo. Psicopatología. Clasificaciones diagnósticas. Espectro. Estructura clínica.

\section{INTRODUÇÃO}

P

ara compreender o autismo, suas abordagens e seu impacto social, é preciso rever a diversidade epistemológica que norteou essa concepção e uma série de outros fatores históricos, políticos e éticos que determinam o lugar conferido ao autismo na civilização atual. $\mathrm{O}$ autismo se tornou um problema de saúde pública. A primeira vez que essa categoria foi introduzida no Manual Diagnóstico e Estatístico de Transtornos Mentais, DSM-III-R (1980), sob a rubrica TGD, transtorno global do desenvolvimento, contabilizou-se uma criança autista em 150. Em abril de 2018, o governo dos Estados Unidos divulgou a atualização dos números do (Centers for Disease Control and Prevention [CDC], 2018): ${ }^{1} 1$ autista para cada 59 crianças. O número anterior era de 1 para cada 68 (referentes a dados de 2012, divulgados em 2016), ocorrendo, portanto, um aumento de 15\% (CDC, 2018). No Brasil ainda não existem dados oficiais sobre as pessoas com Transtorno do Espectro Autista (TEA). De acordo com a "Censos demográficos" (2019), o PLC 139/2018 propôs a obrigatoriedade de inclusão das "especificidades inerentes ao autismo" nos censos populacionais do país.

1 Centros de Controle e Prevenção de Doenças 
São muitas as perguntas suscitadas pelo autismo e pelo aumento significativo das estatísticas mundiais de sua incidência: é genético, qual sua causa, tem cura? Da parte das famílias dos autistas, os pais se veem tomados por preocupações e incertezas diante do enigma do autismo. Eles se dão conta, não sem angústia, de como o convívio com uma criança autista modifica por completo as noções estabelecidas sobre o desenvolvimento infantil, sobre a educação, sobre a socialização. Certamente essas perguntas encontram diferentes respostas a partir do ponto de vista epistemológico, clínico e ético pelo qual se concebe o autismo. Neste artigo, que se fundamenta na orientação lacaniana, vamos introduzir a noção de estrutura autística para além da abordagem espectral do autismo. $\mathrm{O}$ ponto de partida da nossa abordagem é o modo de existir do autista: sua dinâmica e funcionamento subjetivo que dependem da especificidade de sua defesa.

Dois psicanalistas franceses contemporâneos, que foram particularmente sensíveis à causa do autismo, têm contribuído decisivamente para a elaboração teórica do autismo como estrutura clínica: Laurent e Maleval. Eles delimitam o que há de específico em nível do gozo e da linguagem na estrutura subjetiva do autista e que determina o seu modo tão original de ser. Com base no que os autistas nos ensinam, eles têm demonstrado sua lógica e sua dinâmica psíquica. Trata-se de compreender como que um sujeito sem o Outro, absolutamente singular no modo de ser, poderá inventar modos de conexão com o mundo, não sem alguma concessão ao nível da defesa autística, desde que preserve os meios de controle de sua angústia.

Embora a aplicação da psicanálise ao autismo segundo a orientação lacaniana não seja muito divulgada, sobretudo em contextos midiáticos, e que, para muitos, associar psicanálise e autismo ainda pareça impensável, a pesquisa clínica do autismo teve início na década de 1950, particularmente pelo trabalho inédito dos psicanalistas franceses Rosine e Robert Lefort.

\section{A NOÇÃO DE AUTISMO NO CAMPO DA PSICOPATOLOGIA CLÁSSICA}

A palavra autismo foi cunhada por Eugéne Bleuler (1911), um psiquiatra suíço, a partir de sua leitura da teoria da libido de Freud, segundo a qual os seres falantes são feitos de palavras e de libido, mesmo quando não falam. Ao dedicarse ao estudo da esquizofrenia, Bleuler, leitor de Freud, introduziu a causalidade psíquica na psiquiatria clássica. Ele defendia a tese, antes afirmada por Freud e ratificada por Lacan, da spaltung (divisão, clivagem, cisão) ou esquize do sujeito com a realidade como central nos sintomas esquizofrênicos. $\mathrm{O}$ autismo 
foi colocado por ele na série de outros distúrbios da esquizofrenia conhecidos como os quatro "A" de Bleuler: os distúrbios das associações, da afetividade e da ambivalência. Ao extrair o "eros" do "autoerotismo freudiano", criando a palavra autismo para definir a ausência da escolha do objeto e do investimento objetal, Bleuler não deixou de problematizar o desenvolvimento libidinal no autismo. Ele o definiu como perda parcial do contato com a realidade, desvinculação do laço social, isolamento, de maneira que o sujeito se encontra em dois mundos, isto é, o mundo autista e o mundo das relações com o outro, sendo esse último experimentado mais como aparência do que real.

A hipótese, que é freudiana e validada pela casuística já publicada, de que o desligamento do autista com a realidade nunca é total, é indicativa da possibilidade de estabelecer um laço libidinal com o autista (Quinet, 1999). Isso supóe valorizar o apego do autista a determinados objetos, considerados como suas afinidades ou paixões, ponto esse privilegiado pela psicanálise, pois, conforme veremos adiante, eles fazem parte da defesa autística e organizam uma realidade caótica.

De sua inscrição inicial na sintomatologia esquizofrênica no campo das psicoses, norteada pelo encontro de Freud e Bleuler à sua assunção ao estatuto de categoria diagnóstica específica em 1943 na psiquiatria infantil até a atualidade, o autismo se tornou um diagnóstico em expansão e demonstra as mudanças sofridas pelo sintoma a partir da incidência do Outro social na realidade psíquica. As categorias psicopatológicas, os tipos clínicos se mostram mutantes e influenciados por diversos aspectos da sociedade ao longo dos tempos. Lacan recomendou aos analistas que estivessem sempre à altura da subjetividade de sua época. Disso decorre o interesse da psicanálise pela pesquisa do autismo. Ninguém mais do que o autista nos interpela sobre a constituição dos laços sociais e sobre seus impasses na civilização atual.

O autismo infantil precoce foi assim nomeado nos Estados Unidos por Kanner como nova categoria clínica distinta da esquizofrenia. Fiel à epistemologia da clínica médica do século XX e imbuído da metodologia descritiva dos fenômenos que visava a fazer a doença falar, Kanner foi o primeiro a produzir uma narrativa clínica sobre o autismo. Seu ponto de vista eminentemente clínico pode ser lido no artigo que trouxe à luz a tese inaugural do autismo sustentada em detalhada casuística, Os distúrbios autísticos de contato afetivo (1943) (Kanner, 1997). Desse modo, Kanner conferiu um nome ao real do autismo, delimitado por meio dos seguintes traços: solidão em grau extremo, comunicação prejudicada, mutismo, linguagem ecolálica, insistência obsessiva na manutenção da mesmice, ansiedade ante as novas situações, rituais repetitivos, fascinação pelos objetos e desinteresse pelas pessoas, reação angustiante aos signos da presença do outro. 
Até então, crianças com essas ou algumas dessas características eram chamadas de esquizoides.

Com relação à causalidade do autismo, Kanner oscilava entre diferentes posições, ora parecia atraído pelas teorias psicanalíticas pós-freudianas que problematizavam a relação mãe-criança como fator etiológico do autismo; ora, dominado pelo biologicismo, supunha no autista uma incapacidade inata de construir o contato afetivo habitual com as pessoas. Veremos adiante como a noção de autismo de Kanner pluralizou-se de modo tal que temos atualmente uma lista de nomeações: autismo precoce, autismo infantil, autismo de alto nível, autismo atípico, autismo primário, autismo secundário, autismo de Asperger, de Kanner, etc. A hipótese causal do autismo também segue os achados da ciência, que o define como uma disfunção neurobiológica. A psiquiatria infantil, que, influenciada pela psicanálise, estudava os aspectos dinâmicos das patologias, vem privilegiando os aspectos biológicos, centrada na noção de corpo como organismo.

\section{CONTRIBUIÇÕES DOS PÓS-FREUDIANOS: ABORDAGEM PSICODINÂMICA DO AUTISMO}

Tanto nos Estados Unidos como na Europa, ao longo do século XX, verificamos a elaboração de diversas teses sobre o autismo junto aos pós-freudianos, que visavam a avançar na extensão da psicanálise à criança, aos casos de psicose e de autistas. As contribuiçôes dos pós-freudianos, o diálogo com a psiquiatria infantil nascente na década de 1930 nos deixaram uma fecunda casuística, cuja releitura a partir do ensino de Lacan marcou definitivamente um lugar para o autismo nas investigaçôes do campo freudiano. Entre os pós-freudianos e seus achados mais conhecidos, encontramos Margareth Mahler, Bruno Bettelheim, Melanie Klein, Donald Meltzer, Francis Tustin.

A primeira dessa série foi integrante da corrente do ego psychology norteamericana, inspirada na corrente geneticista de Anna Freud. Em virtude da precocidade de sua aparição na infância, o autismo foi, de fato, o problema que mais despertou a atenção das correntes de inspiração psicogenética, nas quais se tornou uma patologia exemplar do tempo pré-verbal, explicada segundo a interação dos fatores constitucionais e ambientais. Em seu livro As psicoses infantis, de 1979, Mahler (1983) relatou o caso de Stanley como paradigmático de sua teoria do autismo como um destino da fase autística normal ou présimbiótica.

A característica de precocidade do autismo detectada pelo renomado psiquiatra infantil, Kanner, inspira aos lacanianos outra leitura menos psicognética e mais 
estrutural da linguagem. Trata-se de investigar a especificidade da relação do ser falante com a linguagem no autismo, mais precisamente, o encontro do infans com a linguagem. "Cada um faz um encontro, no momento da entrada na existência, com a linguagem, com o Outro, com sua presença, sua ausência, suas alternâncias de presença e de ausência. Cada sujeito reage aí de maneira particular" (Stevens, 2008, p. 21).

A incidência da linguagem sobre o corpo do infans é traumática para todos, visto que ela implica um ganho, isto é, a inscrição do ser falante no campo do Outro e, ao mesmo tempo, uma perda tributária da ascensão do organismo vivente ao estatuto de um corpo. São as operaçōes de alienação e de separação que produzem o exílio do gozo do corpo, isto é, um corpo negativizado do ponto de vista do quantum de afeto, doravante submetido às trocas libidinais com o Outro social, o Outro da demanda. A resposta ao trauma pode ser acreditar no poder das palavras, apoiar-se na fala, enlaçar o organismo à língua do Outro para se obter um corpo inserido num discurso. Ao contrário, pode-se ver na linguagem apenas seu poder traumático, não se apoiar na fala, tal como acontece com os autistas. Nesse caso, ocorre um desenlace entre palavras e corpo, pois a defesa autística impede o corpo de ser afetado pelas palavras, deixando-o fora das regras sociais, fora do circuito das demandas. Disso decorre também as desconexões entre linguagem e vida emocional, entre afeto e intelecto, entre corpo e pensamento.

Retomando as concepções pós-freudianas do autismo, Bruno Bettelheim, emigrado da Áustria após a guerra, fundou a Escola Ortogênica de Chicago, na qual cuidava dos autistas afastados de suas famílias. Seu trabalho foi publicado no livro A fortaleza vazia, de 1967 (Bettelheim, 1987), no qual podemos acompanhar, entre outros, o relato do tratamento bem-sucedido de Joey, intitulada a criança-máquina. A contribuição de Bettelheim acabou sendo alvo de críticas que se estenderam à psicanálise até os dias atuais, devido à sua hipótese da "mãe geladeira", isto é, a mãe afetivamente fria, como causadora do autismo. Diferentemente dessa ideia, a orientação lacaniana propõe investigar o estatuto do sujeito anterior à sua determinação pelo laço com o outro, tomado pelo encontro traumático com a linguagem.

De Klein (1970) herdamos o famoso caso Dick, relatado no artigo $A$ importância da formação de símbolos no desenvolvimento do eu, publicado em 1930, portanto, anterior à tese de Kanner (1997). Esse menino despertou na analista grande enigma por ser uma criança completamente diferente de todas que ela conhecera, devido ao fracasso do uso da linguagem e o sofrimento de uma angústia avassaladora do eu, mas que não lhe pareceu compreensível com base nas referências clássicas sobre as neuroses e as psicoses infantis. A releitura 
lacaniana do caso Dick no Seminário 1: os escritos técnicos de Freud, orientou principalmente a compreensão do destino do eu no autismo, isto é, o eu inconstituído, e colocou luz na posição do autista com relação à linguagem: "mestre da linguagem" (Barroso, 2014, p. 287). Quanto a Meltzer, seguidor de Klein, o autismo foi pensado com base no fracasso no funcionamento do self $\mathrm{e}$ das fronteiras do eu.

A Tustin devemos a primeira definição e descrição da especificidade do objeto autístico que captura o investimento libidinal do autista. Ela defendeu a ideia da criança autista como criança encapsulada ou corpo encapsulado, isto é, uma posição defensiva contra a dor da separação. Essa noção foi resgatada por Laurent, ao desenvolver a noção de borda autística, sobre a qual vamos nos deter mais adiante.

Pode-se verificar, na leitura da casuística dos analistas pós-freudianos, que suas contribuiçôes à pesquisa clínica do autismo não desconsideravam os fundamentos freudianos sobre a pulsão e o inconsciente. Dessa maneira, preconizavam um modelo de cuidado predominantemente clínico e não educativo do autista, ou seja, uma abordagem com foco na vida afetiva e pulsional em torno do que se organiza a dinâmica da vida psíquica. A dinâmica psíquica, quer dizer, o funcionamento subjetivo que implica as eleições dos autistas, os objetos autísticos, os interesses específicos, as paixôes, o saber do autista, enfim, a especificidade do mundo feito sob medida para lhe conferir uma satisfação paradoxal e, ao mesmo tempo, um apaziguamento da angústia. Essa especificidade do psiquismo é que não é inclusa no discurso da ciência atual, que se interessa, de modo soberano, pelo conhecimento quase exclusivo da matéria cerebral. Assim, desde as décadas de 1970 e 1980, mediante a evolução da genética e da neurociência, a abordagem da vida afetiva e pulsional do autismo foi sendo deslocada para a abordagem dos problemas do funcionamento da consciência cognitiva. Sob a égide dos manuais DSM, uma visão deficitária do autismo considera o corpo da criança do ponto de vista genético, neurológico, bioquímico, porém não libidinal, tampouco pulsional.

\section{ESPECTRO DO AUTISMO: A EXPANSÃO DO DIAGNÓSTICO}

Nas primeiras edições do DSM, o autismo se manteve associado à psicose, correlacionado ao paradigma psicossocial da psicose ainda presente nessa classificação. A terceira edição do DSM (DSM-III), em 1980, é um marco em termos do avanço do paradigma biologicista, por conferir ao autismo um lugar nos Transtornos Globais do Desenvolvimento (TGD). O termo "global" ou "generalizado" pretendia abarcar o comprometimento da maior parte dos aspectos 
do desenvolvimento, ou seja, aspectos cognitivos, afetivos, sociais, de linguagem, etc. Em seguida, no DSM-IV, em 1994, o autismo foi rebatizado e descrito como sendo de caráter "invasivo", Transtorno Invasivo do Desenvolvimento (TID). Desde o ano 2010, o DSM-V trouxe outra mudança classificatória, isto é, de um transtorno parte de um conjunto de transtornos agrupados na rubrica TID, o autismo passou a nomear esse conjunto, Transtornos do Espectro Autista (TEA). Sob a rubrica TEA, incluiu-se a síndrome de Asperger, que, na quarta versão do manual diagnóstico, constava como um diagnóstico específico.

Wing, psiquiatra e pesquisadora inglesa, cunhou a palavra espectro, que lhe pareceu mais apropriada para expressar as manifestações autísticas de variedade ampla de intensidades e combinaçôes entre pessoas de divergentes capacidades intelectuais e sociais. A influência do estudo da psiquiatra começou na década de 1970, quando ela publicou um livro Autistic children: a guide for parents and professionals (Wing, 1985), no qual buscava falar diretamente com os pais sobre os desafios de criar um filho autista. A novidade dos conselhos do livro foi vislumbrar a possibilidade de convívio familiar com o autista, para quem, até então, era preconizado o tratamento nas instituições.

Com a noção de espectro, Wing expandiu o autismo de Kanner para construir um quadro maior, que, segundo ela, abrigava características do autismo em "um grande número de combinações e em infinitos matizes de intensidade, "até o limite da normalidade” (Donvan \& Zucker, 2016, p. 317). Vejamos então o arcabouço classificatório proposto por ela, chamado tríade da incapacidade. Em primeiro lugar, ela supóe uma incapacidade no conjunto de habilidade social de dar e receber; em segundo, a incapacidade com a linguagem recíproca, inclusive a não verbal; em terceiro, uma deficiência em participar da imaginação social. Essa "tríade da incapacidade" demonstra, de modo contundente, a perspectiva deficitária da qual está imbuída a noção espectral do autismo defendida pela psiquiatra.

\section{$\mathrm{O}$ artigo La dimension spectrale de l'autisme dans le DSM-V et la dit-mension} jouissance (Laia, 2015) discute o que está em jogo numa abordagem espectral do autismo, que supóe a dimensão dos dados estatísticos norteadores das suas classificações. A ciência do DSM classifica o autismo segundo níveis diferentes de gravidade do problema dos déficits na comunicação social e nas relaçôes com os outros. No nível 1, estariam os que demandam um suporte ou apoio; no nível 2, os que demandam um suporte substancial; e, no nível 3, os que demandam um suporte muito substancial.

No entanto, conforme propóe Laia (2015), podemos nos pautar noutra dimensão de caráter propriamente psicanalítico. Para tanto, ele recorre à palavra 
inventada por Lacan, dit-mension, para situar a especificidade do que é do campo do gozo e da palavra. Trata-se da dimensão do afeto, que implica também uma quantidade do ponto de vista econômico do aparelho psíquico, mas que tem outro estatuto: uma quantidade não quantificável, que tem incidência no corpo do ser falante. A teoria do gozo de Lacan ratifica a versão das quantidades freudianas não quantificáveis, tributárias da conexão entre corpo e palavra. É patente como os autores das classificações espectrais do autismo elegeram a referência das neurociências em detrimento das categorias clínicas da psicopatologia (Laia, 2015).

Corroborando uma visão crítica do discurso da ciência sobre o autismo, verificamos que uma avaliação dessa categoria diagnóstica que se baseia apenas no conhecimento do gene e do neurônio promove, na linguagem dita científica, uma articulação do saber a partir, fundamentalmente, das "puras verdades numéricas", isto é, da manipulação do número como tal, a exemplo dos parâmetros estatísticos (Solano, 2011).

Ao lado da instabilidade das classificações diagnósticas do DSM, a psicanálise lacaniana, buscou investigar o que há de constante no autismo, ou seja, qual a lógica e a dinâmica do sujeito que prescindiu do Outro antes mesmo de se servir dele. Se a noção de espectro abriga a dimensão de um continuum de manifestações que podem evoluir dentro de uma mesma categoria, ela não se propõe a explicar a especificidade da vida psíquica no autismo, devido, precisamente, às suas referências epistemológicas. Essa investigação, da qual se ocupa a psicanálise, vem proporcionando um outro olhar para o autismo concebido com base na hipótese de uma estrutura clínica distinta.

\section{ESPECIFICIDADE DA ESTRUTURA DO AUTISMO}

Rosine e Robert Lefort foram os primeiros psicanalistas a formular a hipótese de uma estrutura autística distinta das estruturas da neurose, da perversão e da psicose. Mediante vasta experiência clínica com as crianças, Rosine Lefort soube valorizar e questionar a particularidade da transferência para com o analista que se estabelece distintamente no psicótico e no autista. Suas teses, portanto, advém da observação clínica do lugar conferido ao analista em cada estrutura clínica. Rosine Lefort foi, entre os alunos de Lacan, uma das poucas escolhidas para falar em seu Seminário, no qual teve chance de apresentar os casos clínicos, cuja discussão porta a marca do ensino de Lacan na clínica da psicose infantil e do autismo. Foi Lacan quem the sugeriu escrever sobre os casos que ela atendera na Clínica Parent de Rosan, em Paris, dirigida por Jenny Aubry, 
uma psiquiatra infantil. Entre eles destacamos o caso de Marie Françoise, que se tornou paradigmático da hipótese da estrutura autista.

Quanto à especificidade da transferência do autista, Rosine Lefort salientou a dimensão da violência presente na relação do autista com o mundo exterior e com o outro, violência da pulsão de morte, que pode gerar a destruição e a autodestruição. Esse ponto foi decisivo em sua formulação do estatuto do Outro no autismo, ou melhor a inexistência do Outro, não como alguém, mas como lugar. Ela supôs que os atos violentos do autista teriam como causa o extremo sofrimento advindo pela não inscrição da falta no Outro e a tentativa de inscrever no real essa falta. A presença dos signos da presença real do Outro, da presença de um corpo que não se inscreveu como lugar da troca simbólica, angustia o autista e mobiliza sua defesa. Tanto a voz como olhar são signos da presença do Outro a ser anulada defensivamente.

Por ter constatado a condição do autista de estar imerso no real, Rosine Lefort pôde ser sensível aos problemas da ação devastadora do significante fora do esquema da comunicação, holofraseado, o $S_{1}$ sozinho, cuja lógica exclui o sujeito do campo do sentido e da dialética da linguagem. Quando o autista articula algo, pode-se pensar no estatuto dessa palavra como palavra-objeto que o sujeito conserva nele, sem endereçá-la ao Outro. A marca de gozo não foi extraída da palavra, e falar permanece como uma mutilação para o sujeito que não pode se separar da voz e colocá-la a serviço das trocas com o outro. Não há Outro como lugar do significante nem como lugar da imagem, nem sequer o Outro portador do objeto.

De fato, a abordagem do autismo com base em sua relação original à linguagem é eminentemente lacaniana e pôde avançar, principalmente, a partir da etapa final do ensino de Lacan. Podemos dizer que a infância como tempo lógico implica uma experiência singular, isto é, a de incorporação de uma estrutura que preexiste ao sujeito, a linguagem, a partir de lalíngua, isto é, da dimensão inconsistente e múltipla da língua, massa sonora, plena de equivocidade e geradora do malentendido, que antecede a captura na linguagem. Essa operação de passagem de uma língua privada, que serve prioritariamente ao gozo, à linguagem que serve à comunicação e ao laço social não acontece sem perda.

A observação freudiana do fort-da é ilustrativa do acesso do falasser ao saber pela incorporação da estrutura da linguagem, segundo a qual a oposição de dois significantes, $S_{1}$ e $S_{2}$, inscreve, repetidamente, a perda do objeto inaugural do sujeito dividido. A relação da criança com o saber articulado, o $S_{2}$, funda-se aí, na entrada no discurso. O saber faz borda no furo introduzido pela marca 
traumática imposta pela linguagem sobre o ser vivente, porém sem absorvê-la totalmente.

$\mathrm{Na}$ Conferência em Genebra sobre o sintoma, de 1975 (Lacan, 1998), encontramos comentários decisivos para elucidar os usos da linguagem no autismo e para a sua distinção da psicose:

a) a particularidade da alucinação;

b) o caráter bastante verboso;

c) a desinserção do autista com relação ao discurso do mestre. "Personagens bastante verbosos" (Lacan, 1998, p. 13), assim Lacan definiu os autistas nessa conferência, ao considerar sua relação com as palavras.

Embora estejam fora do discurso, os autistas não são imunes à linguagem. Estamos diante de um sujeito com dificuldade de tomar a posição de enunciador, pois experimenta uma carência de identificação ao nível do ser, devido a um problema na sua constituição subjetiva, precisamente, uma perturbação na alienação do ser vivente à linguagem. Seja no mutismo, seja utilizando a palavra como uma espécie de ventríloquo do outro, seja emitindo verbalizações que Kanner chamava de ecolalia ou linguagem de papagaio, o fato é que o autista demonstra vários distúrbios da enunciação, o que faz com que ele se desincumba de colocar em jogo sua voz, sua presença e seus afetos (Acero, 2013).

Por trás da variedade do uso original da língua pelo autista, Maleval (2017) encontra uma constante: o desfuncionamento pulsional. $O$ traumatismo resultante do encontro entre o ser vivo e a língua é tão insuportável para o autista que ele não cede sua voz à articulação pulsional com o Outro. Essa recusa em ceder o gozo vocal obstaculiza sua inscrição no campo do Outro e a cifração do gozo por meio do traço unário. Ainda que o autista venha a fazer um uso da língua, a presença da enunciação que ligaria a voz ao campo da linguagem é evitada por ele. A apropriação da linguagem não opera pelo enganche do significante à voz, mas pela assimilação de signos referidos a imagens. A construção da realidade no autismo se faz com o signo. O sujeito é levado a operar correlações rígidas termo a termo, a privilegiar a literalidade, a evitar as noçôes mais abstratas que lhe parecem de difícil assimilação e assegurar, dessa maneira, a imutabilidade de seu ambiente. A lógica do signo pode afetar o objeto de certa negatividade, porém sem que se produza uma assunção de sua perda, tal como ocorre quando a realidade é construída por meio do significante (Maleval, 2017). 
Desde a publicação do livro O nascimento do Outro (Lefort \& Lefort, 1984), acompanhamos a investigação da possibilidade, que se revelou muitíssimo improvável, de haver uma saída do autismo. Se, de início, essa solução como uma espécie de psicotização do autista foi suposta, a elaboração posterior do mecanismo que implica a causalidade psíquica do autismo, isto é, a forclusão do furo, separou a estrutura do autismo da estrutura psicótica. A forclusão do furo quer dizer que não ocorreu a operação causa do nascimento do Outro para o sujeito, a saber, a extração do objeto do campo da realidade.

Esse mecanismo, isto é, a forclusão do furo, que explica a dinâmica subjetiva do autista, foi evocado, primeiramente, por Miller a propósito do caso Robert, atendido por Rosine Lefort, para explicar a tentativa de automutilação feita por esse menino com relação a seu órgão genital. No artigo La matrice du traitement de l'enfant au loup (Miller, 2007), Miller lê esse ato como a entrada em função do menos que tenta se inscrever no real, visto que não houve, para o sujeito, a inscrição simbólica do furo que seria promovido pela incorporação da linguagem. Por não dar lugar simbólico à falta em seu mundo, o autista vai produzi-la no real (Miller, 2007).

Laurent, no livro $A$ batalha do autismo, publicado no Brasil em 2014, estendeu ao autismo a noção lacaniana de forclusão, que explica a lógica dos fenômenos de linguagem e de gozo nas psicoses, porém diferenciando a forclusão do Nome do Pai e a forclusão do furo. Enquanto a primeira incide no significante, na dimensão do Outro simbólico, a segunda incide na dimensão do real. Quando o estatuto do Outro é simbólico, trata-se de um Outro portador de um furo que tem uma borda conferida ao corpo pela inscrição da castração, pela extração do objeto e pela imagem corporal. No autismo falta a delimitação de uma borda simbólica desse furo, o que promove o encapsulamento por uma neoborda e o retorno do gozo sobre a borda, diferentemente da paranoia e da esquizofrenia, cujo gozo retorna no Outro ou no corpo, respectivamente.

O retorno do gozo sobre a borda quer dizer que o gozo retorna numa zona fronteiriça, isto é, uma borda que possa delimitar o furo, lugar onde contatos e trocas com a realidade poderão vir a ocorrer, o que supóe, conforme já foi dito antes, a possibilidade de conexão com o sujeito autista. A neobarreira corporal instala-se onde a imagem não socorreu o corpo para fazer-lhe contornos, demonstrando o desenlaçamento entre o real e o imaginário. $\mathrm{O}$ autista conta, portanto, apenas com essa borda como superfície corporal, isto é, uma espécie de cápsula que lhe serve de defesa das manifestaçôes do Outro real. A exemplo da cápsula do astronauta, ela lhe permite deslocar-se no universo e explorá-lo. Trata-se de formação protetora que dispõe de três componentes principais: o objeto autístico, o duplo e as ilhas de competência que concernem ao saber do 
autista. A função da borda autística é fazer suplência à forclusão do furo. Ela estabelece um modo de relação entre dois campos distintos, o corpo e a língua. E permite ao autista livrar-se de seu estado de retraimento no corpo encapsulado, conforme puder fazer concessões estratégicas em seu funcionamento.

Considerando que, no autismo, os trajetos pulsionais parecem estar ausentes devido à forclusão do furo, Laurent (2014) observa no livro A batalha do autismo que, no lugar desses trajetos, aparecem os circuitos do objeto articulados ao corpo por bordas de gozo, que implicam uma topologia particular do espaço próprio do sujeito autista.

Chamamos de "objeto" o acomodamento dos restos, dos dejetos, deixados pelo encontro com o Outro da língua que vem perturbar o corpo, seja qual for o substrato biológico do funcionamento ou da disfunção de tal corpo. O objeto é essa cadeia heterogênea, feita de coisas descontínuas (letras, pedaços de corpo, objeto tirados do mundo [. . .]), organizada como um circuito, munida de uma topologia de borda e articulada ao corpo (Laurent, 2014, p. 89).

O circuito autístico é desenhado pelo trabalho com a letra, com base no significante sozinho e sua metonímia, promovendo a autodefesa e autoconstrução do sujeito autista. Acolher esse trabalho, esforçar-se para entrar no mundo do autista a partir de uma posição ética psicanalítica, supõe um consentimento às invenções sob medida para cada um. "A invenção é o único 'remédio' do sujeito autista e deve incluir, a cada vez, o resto, ou seja, o que permanece no limite de sua relação como o Outro: seus objetos autistas, suas estereotipias, seus duplos" (Laurent, 2014, p. 78)

No artigo Lacan e o autismo em nossa época, Tendlarz (2017) discute a orientação de um tratamento possível do autismo conferindo à noção de borda um papel fundamental da direção da cura, isto é, uma questão preliminar ao tratamento. Além de preservar eticamente o respeito à singularidade do autista, essa orientação implica uma clínica dos circuitos pulsionais, que supõe o modo específico de retorno do gozo no autismo. Trata-se de um divisor de águas entre a contribuição da psicanálise e os outros métodos de cunho cognitivista, que se baseiam exclusivamente no funcionamento deficitário da percepção e da cognição do autista (Tendlarz, 2017).

Ao encontrar do lado do psicanalista um parceiro em sua construção, verificamos que o autista estende, amplia e transforma a borda defensiva e dinâmica em direção ao laço social. Para tanto, é preciso que o analista se deixe incluir de modo singular em cada caso, por exemplo, por meio de seu corpo, de gestos, de modalizações da voz e do olhar, mediante objetos e palavras; e, enfim, por seu ato. 


\section{CONSIDERAÇÕES FINAIS}

Como se pôde verificar ao longo deste artigo, os paradigmas norteadores das abordagens do autismo são diversos. Os psicanalistas de orientação lacaniana se empenham na pesquisa em conexão com outros campos de saber sobre o autismo. A proposta da "prática a partir de vários" (Ciaccia, 2005, p. 34), iniciada em 1994 pelos lacanianos na instituição para crianças autistas e psicóticas chamada Antenne 10, situada nas proximidades de Bruxelas, na Bélgica, é uma demonstração do esforço da aplicação da psicanálise ao autismo.

Além disso, o estudo dos testemunhos dos autistas e dos seus escritos se tornou uma referência fundamental para a formulação da hipótese de uma estrutura autística. A escrita do autista transmite sua relação à língua e à linguagem, sua maneira original de pensar, de apreender a língua, de se defender da angústia fechado, ensimesmado, num mundo por ele inventado. Entre os livros dos autistas mais estudados citamos o de Tammet (2007), Nascido num dia azul; o de Grandin (1999), Uma menina estranha; o de Williams (2012), Meu mundo misterioso; e o de Higashida (2014), O que me faz pular.

A psicanálise se posiciona hoje, decididamente, do lado da pesquisa do autismo. Ela tem muito o que aprender com o autista também para elucidar a subjetividade contemporânea, pois nesta encontramos traços de um autismo generalizado, evidenciado nos impasses do laço social de nossa época. A interlocução com outros saberes é bem-vinda. Abre novas parcerias de trabalho. Exemplo disso é o livro intitulado $A$ cada um seu genoma, escrito por François Ansermet, um psicanalista, e Ariane Giacobino, uma geneticista (Ansermet \& Giacobino, 2015). Ambos compartilham de um achado importante: a absoluta singularidade autística, tanto do ponto de vista do genoma como do ponto de vista do modo original de ser.

Com relação à educação e à aprendizagem do autista, abre-se outro espaço de conexão, isto é, psicanálise e pedagogia. A palavra "inclusão" torna-se cara a esses dois campos teóricos e práticos e instiga o debate. Uma série de perguntas, como as que se seguem, são de interesse da clínica e da educação do autista: no lugar de incluir o autista no programa do Outro escolar, o que frequentemente constrange suas invenções singulares, não seria interessante propor o inverso, ou seja, a inclusão do Outro escolar nas iniciativas do autista? Como não dissociar a aprendizagem da dinâmica subjetiva do autista? A noção de borda autística poderia contribuir com açōes educativas propícias ao enlaçamento da aprendizagem à vida afetiva, de maneira a viabilizar uma verdadeira autonomia do autista? 
Para concluir, vemos que a oferta da psicanálise ao autismo é mais do que uma teoria da estrutura autística. Também não se reduz a uma técnica específica. Apostamos num reencontro menos traumático do autista com a linguagem, com o outro, que viabilize alguma flexibilização da sua defesa e a construção da sua existência. Trata-se de priorizar uma ética que não se orienta pelos ideais adaptativos universais. Muito além de qualquer referência diagnóstica classificatória do autismo, distinta de toda visão deficitária, a prática orientada pela psicanálise investe na construção do caso, que constitui uma das principais metodologias da nossa pesquisa. Dando lugar à singularidade, sustentamos a investigação do caso a caso, para saber o que é, para cada um, o seu autismo. 


\section{REFERENCIAS}

Acero, I. R. (2013). O que dizem os autistas. I. A. D. Barbosa (Trad.). Opção Lacaniana, Ano 4, 11. Recuperado a partir de http://www.opcaolacaniana.com.br/pdf/numero_11/autistas.pdf

Ansermet, F., \& Giacobino, A. (2015). Autismo: a cada um o seu genoma. Petrópolis: KBR Digital.

Barroso, F. S. (2014). As psicoses na infância: o corpo sem a ajuda de um discurso estabelecido. Belo Horizonte: Scriptum.

Bettelheim, B. (1987). A fortaleza vazia. São Paulo: Martins Fontes.

Censos demográficos terão dados sobre pessoas com autismo. (2019, 2 julho). Brasília: Agência Senado. Recuperado a partir de https://www12.senado.leg.br/noticias/materias/2019/07/02/censosdemograficos-terao-dados-sobre-pessoas-com-autismo

Centers of Disease Control and Prevention. (2018). Data \& Statistics on Autism Spectrum Disorder. Atlanta: CDC. Recuperado a partir de https://www.cdc.gov/ncbddd/autism/data.html

Ciaccia, D. A. (2005). A prática entre vários. In S. Altoé \& M. Lima (Orgs.), Psicanálise, clínica e instituição. (pp. 34-54). Rio de Janeiro: Rios Ambiciosos.

Donvan, J., \& Zucker, C. (2016). Outra sintonia: a história do autismo. São Paulo: Companhia das Letras.

Grandin, T. (1999). Uma menina estranha: autobiografia de uma autista. São Paulo: Cia. das Letras.

Higashida, N. (2014). O que me faz pular. Rio de Janeiro: Intrínseca.

Kanner, L. (1997). Os distúrbios de contato afetivo. In P. S. Rocha (Org.), Autismos. (pp. 111-170). São Paulo: Escuta.

Klein, M. (1970). A importância da formação de símbolos no desenvolvimento do eu: contribuições à psicanálise. São Paulo: Mestre Jou.

Lacan, J. (1998). Conferência em Genebra sobre o sintoma. Opção Lacaniana, Revista Brasileira Internacional de Psicanálise, 23, 6-16. 
Laia, S. (2015). La dimension spectrale de l'autisme dans le DSM et la ditmension jouissance. In M. Perrin (Org.), Affinity therapy nouvelles recherches sur l'autisme. (pp. 259-264). Rennes: Presses Universitaires de Rennes.

Laurent, E. (2014). A batalha do autismo. Rio de Janeiro: Zahar.

Lefort, R., \& Lefort, R. (1984). Nascimento do Outro: duas psicanálises. A. Jesuino (Trad.). Salvador: Fator.

Mahler, M. (1983). As psicoses infantis e outros estudos. Porto Alegre: Artes Médicas.

Maleval, J. C. (2017). O autista e sua voz. São Paulo: Blucher.

Miller, J.-A. (2007). La matrice du traitement de l'enfant au loup. La Cause Freudienne, 66, 141-151.

Quinet, A. (1999). A psicopatología da esquizofrenia: Bleuler com Freud e Lacan. In S. Alberti (Org.), Autismo e esquizofrenia na clínica da esquize. (pp. 79-107). Rio de Janeiro: Rios Ambiciosos.

Solano, E. (2011). Aletosfera. In Associação Mundial de Psicanálise (Org.), Scilicet, a ordem simbólica no séc. XXI. (pp. 28-30). Belo Horizonte: Associação Mundial de Psicanálise \& Scriptum.

Stevens, A. (2008). Aux limites du lien social, les autismes. Les Feuiliets du Courtil, 29, 9-28.

Tammet, D. (2007). Nascido em um dia azul: por dentro da mente de um autista extraordinário. Rio de Janeiro: Intrínseca.

Tendlarz, S. E. (2017). Lacan e o autismo em nossa época. Opção Lacaniana, Ano 8, 23. Recuperado a partir de http://www.opcaolacaniana.com.br/pdf/numero_23/Lacan_e_o_autismo_ em_nossa_epoca.pdf

Williams, D. (2012). Meu mundo misterioso: testemunho excepcional de uma jovem autista. Brasília: Thesaurus.

Wing, L. (1985). Autistic children: a guide for parents and professionals. New York: Brunner, Mazel. 